\title{
Identification and Isolation of the Yeasts in Traditional Yogurts Collected From Villages in Gaziantep,Turkey
}

\author{
Ayşe Karaduman', Mehmet Özaslan', Ibrahim H Kilic*1 and Sibel Bayıl Oğuzkan ${ }^{2}$ \\ ${ }^{1}$ Department of Biology, Arts and Science Faculty, Turkey \\ ${ }^{2}$ Department of Medical Services and Techniques, Vocational School of Health Services, University of Gaziantep, Gaziantep, Turkey
}

*Corresponding author: İbrahim Halil Kılıç, Department of Biology, Arts and Science Faculty, Turkey

\begin{tabular}{|c|c|}
\hline ARTICLE INFO & ABSTRACT \\
\hline Received: 啡 January 24, 2019 & \multirow{8}{*}{$\begin{array}{l}\text { Yogurt is one of the most common fermented milk products in the world. It is produced } \\
\text { by the addition of homofermentative lactic acid bacteria (LAB) and some yeasts to milk and } \\
\text { is a LAB fermentation product. Therefore, yogurt contains large quantities of LAB and their } \\
\text { metabolites, which are beneficial to human health. In this study, } 208 \text { tradational yoghurt } \\
\text { samples were collected from } 9 \text { different locations from villages in Gaziantep Province. The } \\
\mathrm{P}^{\mathrm{H}} \text { values of the yogurts ranged from 3.9-6.0. After yeast isolation from the yogurts that } 25 \\
\text { samples were showed including yeast, the total number of their ranged from } 1-1.8 \times 10^{8} \\
\text { CFU/g on MRS agar. MALDI TOF MS was used for yeast identification. Among the isolates, } \\
52 \% \text { were Candida kefyr, 36\% were Saccharomyces cerevisiae, 8\% were Candida tropicalis } \\
\text { and } 4 \% \text { Candida lypolitica. These results showed that traditional yogurts collected from } \\
\text { villages in Gaziantep Province contain various contamined yeast; they are detrimental for } \\
\text { human healthy on yogurt production. }\end{array}$} \\
\hline Published: February 01, 2019 & \\
\hline Ayșe K, Menmet o, Ibrar & \\
\hline & \\
\hline & \\
\hline Yogurts Collected From Villages in & \\
\hline $\begin{array}{l}\text { iantep,Turkey. Biomed J Sci \& Tech } \\
13(5)-2019 \text { BISTR MS ID 002478 }\end{array}$ & \\
\hline & \\
\hline
\end{tabular}

Keywords: Candida spp; Contamined; Saccharomyces Cerevisiae; Yeast; Yogurt

\section{Introduction}

During the fermentation of foodstuffs, the main physical and chemical changes occur due to the growth and fermentative activity of the LAB that are used as starter cultures. LAB are used as starter cultures for the fermentation of milk [1]. Yogurt is a milk product that is obtained by the bacterial fermentation of milk. Lactic acid is produced via the fermentation of milk sugar, also known as lactose. Lactic acid is the substance that confers the typical textural and sensory characteristics of yogurt and acts on milk protein [2]. Besides low asid is a suitable environment for the life of yeasts. Fermented products also contain yeasts. They have created positive effects on the bacteria via $\mathrm{P}^{\mathrm{H}}$ changing and biological substances releasing [3]. If a matter of caution is to be taken, they may be causing of the spoilage in fermented product.

Yogurt contains high concentrations of LAB and the smaller yeast have several potential health benefits and probiotic potential; it can increase lactose tolerance, balance the intestinal microflora, act as an antimicrobial, stimulate the immune system, induce antitumor effects, and induce anti-cholesterolemic effects. Yeast may be some aroma components and interact with LAB that are primer starter cultures. Yeast growth stabilizes LAB which are starter culture [4]. Knowledge of the biochemical properties of the starter cultures is necessary to determine the final characteristics of the fermented food product, such as its acidity, aroma and flavor. To gain such knowledge, it is crucial to identify and characterize the yeast in a starter culture. The aim of this study was to identify of the yeast that could be isolated from traditional yogurts collected from villages in Gaziantep Province. Additionally, preliminary information was prepared to create reliable yogurt in respect to pathogen microorganisms.

\section{Material and Methods}

\section{Sample Collections and $\mathrm{P}^{\mathrm{H}}$ Measurement}

Yeasts were isolated from traditional yogurts collected in villages in Gaziantep Province (from Sahinbey, Sehitkamil, Oguzeli, Yavuzeli, Nizip, Karkamis, Araban, Islahiye and Nurdagi townships) between 2015-2016 years. The $\mathrm{P}^{\mathrm{H}}$ values of 208 the yogurt samples were measured with a $\mathrm{P}^{\mathrm{H}}$ meter (Martini Instruments, Romania) and recorded.

\section{Isolation and Total Yeast Counts}

The samples were diluted before culturing on MRS (de Man, Rogosa and Sharpe) agar (Oxoid, England). The MRS plates were incubated for 3 days in aerobic environments at $30^{\circ} \mathrm{C}$ [5-7]. All of the suspect colonies in petri dishes were recorded as CFU/g [6]. 


\section{Stock Culture Preparation}

A sterile loop was used to sample colonies and to inoculate them into Eppendorf tubes containing $1 \mathrm{ml}$ of MRS Broth (Oxoid, England). Yeast samples inoculated into MRS were incubated for 48 hours. Stocks were prepared from $500 \mu$ l of yeast cultured in MRS broth $500 \mu \mathrm{l}$ of sterile liquid glycerol that were mixed in a $1 \mathrm{ml}$ Eppendorf tube and stored at $-20^{\circ} \mathrm{C}[8]$.

\section{Identification of Yeasts Using MALDI-TOF MS}

Identification of yeast colonies isolated from traditional yogurts was conducted according to their protein and peptides database analysis using MALDI-TOF MS. Matrix-assisted laser desorption ionization-time of flight mass spectrometry (MALDI-TOF MS) is a new technology application for identify yeast cultures. Avantages of this application have got faster and routine properties [9]. For these tests, stock cultures were grown on MRS agar. The isolates were tested with respect to their various surface proteins. Twenty-five isolates were selected for yeasts identification by the MALDI-TOF MS (BioMérieux, France) test kit. Data were subjected to evaluation as a percentage (\%).

\section{Results}

According to the results of this study, the pH values of 208 yogurt samples ranged from 3.9 to 6.0. The average $\mathrm{P}^{\mathrm{H}}$ of the yogurts ranged between 4.30 and 5.14 as seen Table 1 . The total yeast counts on MRS agar medium were 1-1.8 x $10^{8} \mathrm{CFU} / \mathrm{g}$ following the isolation of yeasts from the yogurt samples. Seventy four (74) colonies out of 25 analyzed yogurt samples were identified on MRS medium as the yeast. The yeast identification results revealed that the mycoflora in yogurt from Gaziantep Province, Turkey contained 52\% Candida kefyr, 36\% Saccharomyces cerevisiae, 8\% Candida tropicalis, $4 \%$ Candida lypolitica. The distribution of different yeasts (\%) among yogurts collected from townships in Gaziantep Province is shown in Figure 1.

Table 1: The PH values of yoghurts collected from villages in Turkey.

\begin{tabular}{|c|c|}
\hline Villages & The average PH \\
\hline A1 $(n=30)$ & 4,30 \\
\hline A2 $(n=30)$ & 4,40 \\
\hline A3 (n=30) & 4,43 \\
\hline A4 (n=15) & 4,35 \\
\hline A 5 (n=15) & 4,97 \\
\hline A 6 (n=15) & 4,35 \\
\hline A 7 $(n=28)$ & 4,63 \\
\hline A8 (n=15) & 4,43 \\
\hline A9 $(n=30)$ & 4,43 \\
\hline
\end{tabular}

\section{The percentage of the isolates (\%)}

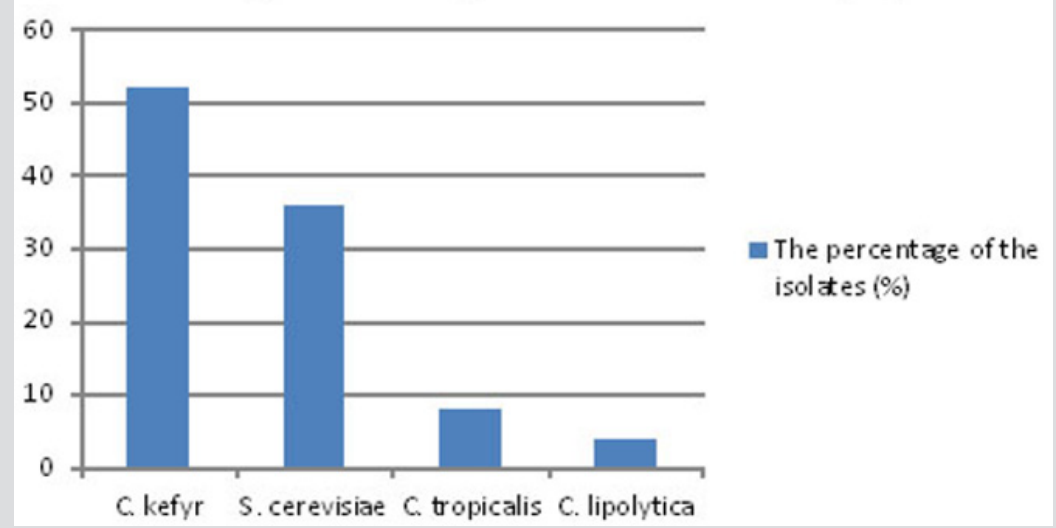

Figure 1: The distribution of different yeasts (\%) among yogurts collected from townships in Gaziantep Province.

\section{Discussion}

The present study is the first to specifically analyze the yogurt mycoflora in Gaziantep Province. In this study, the results showed that the $\mathrm{P}^{\mathrm{H}}$ levels of traditional yogurts from Gaziantep were acidic (below 7) as a result of lactic acid fermentation. The $\mathrm{P}^{\mathrm{H}}$ of the yogurts ranged from 3.9-6.0. The animal sources of the yogurts varied; they included cow milk, sheep milk and goat milk. It has been determined that the $\mathrm{P}^{\mathrm{H}}$ levels of yogurts produced from different milk types ranged between 4.02 and 4.26 and reported that these $\mathrm{P}^{\mathrm{H}}$ values were related to the metabolic activity of the starter cultures and the fermentation time of the yogurt [10]. Meanwhile, it has been showed that the $\mathrm{P}^{\mathrm{H}}$ values of yogurts obtained from villages in Nigeria were between 3.80 and 4.48 [11]. Additionally, they reported that these levels were lower than the $\mathrm{P}^{\mathrm{H}}$ levels of commercial yogurts. Yeast isolation studies were carried out from fermented milk products in several countries. C. tropicalis has been isolated from Tanzania fermented milk. But, the same yeast species has not isolated from yogurt samples.

Researches said that yeast contamination has been prevented and controlled is importance on fermented dairy producing [12]. Kavas et al. [4] have isolated these yeast species from isolated from İzmir, Turkey [4]. They have identified the yeast species which inhibit yogurt starter cultures growth. For this reason yeast contamination should been blocked. In present study, [12] 
percentage of two hundred and eighty (208) were the yeast species. But, these yeasts are not also indigenous in yogurt normally. For this reason, the yeasts isolated from the yogurts are worrying for consumer health and their control is necessary. Contamine yeasts needs to be controlled. On the other hand these yeasts may be play a severity role the ending of fermentation. Besides it is gratifying that these yogurt samples are not contain toxigenic yeasts such as Penicillum, Aspergillus. While Omokaro et al. [13] 20\% 20\% Saccharomyces cerevisiae have isolated from Nigeria yogurt samples, this rate was $36 \%$ in present study [13]. Saccharomyces may be related to suitable flavor development and Candida spp. yeasts that have got protease activity would long shelf life of milk products, also enhancing activation in LAB fermentation [12]. The Candida species were the predominant among 25 yeasts species including 16 Candida (64\%) and 9 Saccharomyces (36\%).

In this study, Candida kefyr, Candida lypolitica, Saccharomyces cerevisiae isolated from traditional yogurts were also isolated from traditional fermented camel milk in a previous study [3]. The present study has showed that yogurt fermented dairy food comprise yeast microflora. Yeasts interact with other microorganisms [12] and yeasts are consist secondary flora in fermented milk products [14] isolated sixteen species belonging to Candida and Saccharomyces genus from Pakistan yogurt samples. But these yeast species are out of our isolated yeast species [15]. Biberoglu and Ceylan (2013) found as 50\% Candida kefyr,23.95\% Saccharomyces cerevisiae, 4\% Candida lypolitica same results with our present study from yogurt samples of Erzurum and Kars regions, Turkey [14]. Soulides (1956) isolated lactose fermented Torulacremoris from yogurt. New name of this species in binominal named is Candida pseudotropicalis [16].

We isolated several Candida species in too, in present study. Moreira et al. [17] found 19\% Saccharomyces cerevisiae rate from Brazil yogurts [17]. This rate was 36\% in traditional yogurt samples, Gaziantep, Turkey in our study. Saccharomyces cerevisiae and Candida spp. which are contained yeasts causing spoilage in traditional yogurt production, were isolated in this study. However, theyeast species thatwe isolated have previouslybeen demonstrated to have the potential harmful ability to produce yogurt. These species may represent factors that is to be need underlie hygiene properties of traditional yogurts. These contaminants must be struggled. In a sense important results have been obtained for the provision of traditional yogurts to consumers in our city. This study may represent a fundamental investigation for eliminated contained yeasts during the yogurt production process, as isolated bacterial species that have previously been isolated in other studies. The four different kinds yeast of in these yogurts samples have been isolated in this study. In the data obtained is a preliminary study and firstly study in this region which will be useful information to another region for this non-commercial yogurt.

\section{Conclusion}

Our study researches the basic development of suitable hygiene conditions for traditional yogurt production. So far, there has been little specific research on yogurt contained microflora in Turkey. Our study is the first to specifically analyze the yogurt contaminants in Gaziantep Province, Turkey.

\section{References}

1. Panesar PS (2011) Fermenteddairyproducts: startercultures ad potential nutritional benefits. Sci.Res. 2(1): 47-51.

2. Arican A, Andic S (2011) Survival of E. Coli 0157:H7 in yoghurt incubated until two different $\mathrm{P}^{\mathrm{H}}$ values and stored at $4^{\circ} \mathrm{C}$. Kafkas Univ Vet Fak 17: 537-542.

3. Yam BZ, Khomeiri M, Mahounak AS, Jafari SM (2015) Isolation and Identification of yeasts and lactic acid bacteria from local traditional fermented camel milk, Chal. J Food Proess Technol 6: 1-6.

4. Kavas G, Kinik O, Uysal H, Kilic S, Celikel N, et al. (2006) Characterisation of yeasts Isolated from artisanal Turjish dairy products. Intl J Dairy Sci 1: 44-50.

5. Khedid K, Faid M, Mokhtari A, Soulaymani A, Zinedine A (2006) Characterization of lacticacid bacteria isolated from the one humped camel milk produced in Morocco. Microbiol Res 164: 81-91.

6. Omemu AM, Faniran OW (2011) Assessment of the antimicrobialactivity of lacticacid bacteria isolated from two fermented maize products ogiandkannu-zaki. Malays J Microbiol 7: 124-128.

7. Iranmanesh M, Ezzatpanah H, Mojgani N, Torshizi MAK, Aminafsshar $\mathrm{M}$, et al. (2012) Isolation of lacticacidbacteriafromewemilk, traditional yoghurt and sour butter milk in Iran. Eur FoodRes \&Rev 2(3): 79-92.

8. Azadnia P, Khan Nazer AH (2009) Identification of lactic acid bacteria isoleted from traditional drinking yoghurt in tribes of Fars province. Iranian J Vet Res 10: 235-240.

9. Chalupová J, Raus M, Sedláŕová M, Śebela M (2013) Identification of fungal microorganisms by MALDI-TOF massspecrometry. Biotech Adv 11: $1-12$.

10. Erkaya T, Sengul MA (2012) Comperativestudy on some quality properties and mineral contents of yoghurts produced from differenttype of milks. Kafkas Univ Vet Fak 18: 323-329.

11. Omafuvbe BO, Enyioha LC (2011) Phenotypic identification and technological properties of lacticacid bacteria isolated from selected commercial Nigerian bottled yoghurt. Afr J Food Sci 5: 340-348.

12. Mlimbila JS, Hosea KM, Muruke M (2013) Molecular identification and proteinase of yeasts isolated from fermented milk. Int J D Sci Res 2: 7-14.

13. Omokaro 0, Berembo BT (2014) Microorganisms associated with street vended yoghurt in mile 1 Diobu area of port harcourt, Nigeria. EJ Sci Technol 5: 179-186.

14. Biberoglu O, Ceylan ZG (2013) Isolation and identification of yeasts from traditional yoghurts and some microbiological properties J Anim Vet Adv 12: 1250-1255.

15. Mushtaq M, Iftikhar F, Nahar S (2006) Detection of yeast mycoflora from milk and yogurt in Pakistan. Pak J Bot 38: 859-868.

16. Soulides DA (1956) Lactose-fermenting yeasts in yoghurt and their effect upon yhe product and the bacterial flora. J Delaware U Bio Sci 4(5): 274-276.

17. Moreira SR, Schwan RF, Carvalho EP, Wheals AE (2001) Isolation and identification of yeasts and filamentous fungi from yoghurts in Brazil. Brazilian J Mic 32(2): 117-122. 


\section{ISSN: 2574-1241}

DOI: 10.26717.BJSTR.2019.13.002478

İbrahim Halil Kılıç. Biomed J Sci \& Tech Res

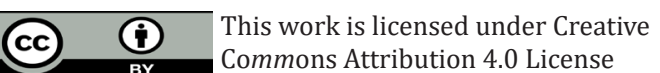

Submission Link: https://biomedres.us/submit-manuscript.php

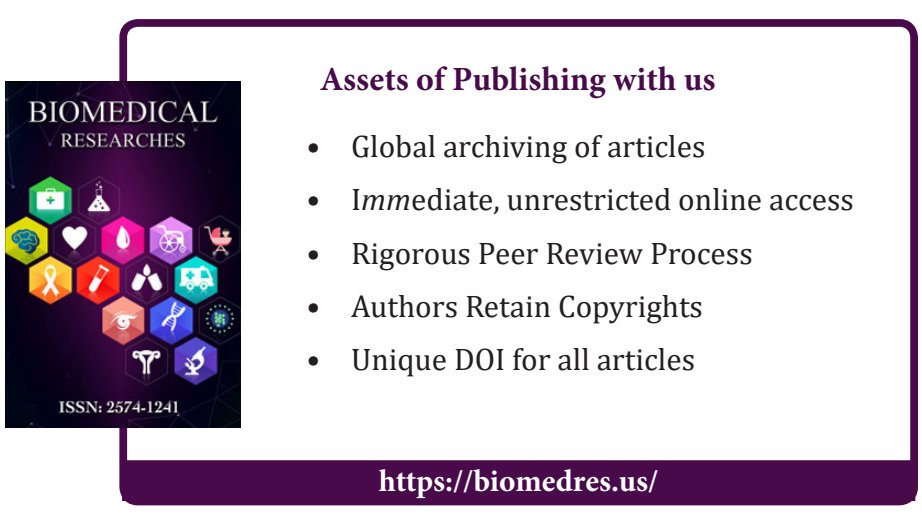

